\title{
Do Asset Managers Pose a Systemic Risk?
}

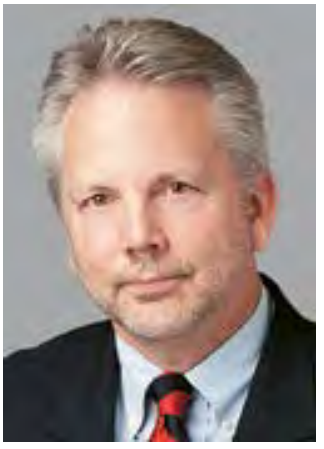

By Kurt N. Schacht, JD, CFA

Remember the great financial crisis, when financial institutions were on the brink of implosion and governments were scrabbling together emergency support measures to prevent a global collapse? It seems like a distant memory-unless you are a regulator charged with preventing another episode. We have seen multiple new rules to rein in financial leverage and excess at banks and other institutions. Next on the radar is the investment management industry.

The question of whether asset managers pose a systemic risk to the financial system is a controversial one. In the United States, ever since the Office of Financial Research (OFR) released a report in 2013 hinting that asset managers were next in line for designation as "significantly important financial institutions" (or SIFIs), vocal critics-mainly the largest asset managers-have argued forcefully that the asset management industry is different and does not pose a risk to financial stability. Similar debates are occurring in European markets as well. Meanwhile, some industry observers, including even some smaller asset managers, have expressed concern that a run on the world's largest players would have much broader (and more dangerous) implications for systemic risk.

\section{WHERE DOES CFA INSTITUTE STAND ON THE ISSUE?}

CFA Institute noted its support for further review of the issues back in 2013 - that is, for having the OFR objectively conduct research on issues related to financial stability. In the end, that research lacked readily available data to support OFR determinations about asset managers' activities and whether they posed significant systemic risk. Moreover, the report gave little weight to the fact that existing federal regulations under which many asset managers fall already restrict a number of activities that the report suggests would amplify risk. Thus, we urged additional research and analysis before reaching conclusions about whether stricter and more onerous banking and Federal Reserve regulation is needed for this industry.

Regulators ultimately put off asset manager SIFI designations and instead solicited public comment on the potential risks to US financial stability from asset management products and activities (specifically, liquidity and redemptions, leverage, operational functions, and resolution in the asset management industry). As previously noted, it is not a US issue only-the Financial Stability Board and the International

Organization of Securities Commissions have sought public comment on proposed methodologies for identifying globally active, systemically important investment funds.

CFA Institute supports the monitoring of asset management firms by existing regulators for their potential to create risks to the financial system because we recognize how the use of leverage, inability to delay redemptions, and significant asset concentrations could transmit problems throughout the financial system. Additionally, this existing oversight is coupled with regulations already covering asset managers, large and small, from amassing huge leverage and permitting the use of mechanisms, such as "gating," to modulate redemptions. Even those that are permitted to use leverage-hedge funds and exchange-traded products-have built-in protections, including market-based pricing, that mitigate the potential for systemically transmitted failure.

\section{WE URGED ADDITIONAL RESEARCH AND ANALYSIS BEFORE REACHING CONCLUSIONS ABOUT WHETHER STRICTER AND MORE ONEROUS BANKING AND FEDERAL RESERVE REGULATION IS NEEDED FOR THIS INDUSTRY.}

In the final analysis, asset management is fundamentally different from bank and insurance institutions in that, beyond the mechanisms noted previously, asset managers typically don't own the assets they manage, which usually consist of publicly traded, more marketable, and more liquid securities.

CFA Institute does support and encourage efforts for an ongoing assessment of potential systemic risk posed by the asset management industry. It supports stronger oversight and regulatory refinements in this regard by existing regulators. Accordingly, a decision to introduce and overlay the existing system with a further set of regulations and regulators less knowledgeable and experienced with the sector's business models must be well founded.

KEEP GOING

Follow the Market Integrity Insights blog: http://blogs.cfainstitute.org/ marketintegrity

Follow us on Twitter: @MarketIntegrity
As it stands, such an action would be very costly, inefficient, and unsupported by the reviews conducted.

Kurt Schacht, JD, CFA, is managing director of Standards and Market Integrity at CFA Institute. 